\title{
Erratum to: Homogenization of Tianjin monthly near-surface wind speed using RHtestsV4 for 1951-2014
}

\author{
Peng $\mathrm{Si}^{1}$ • Chuanjun Luo ${ }^{1}$ - Dongpo Liang ${ }^{2}$
}

Published online: 6 July 2017

(C) Springer-Verlag GmbH Austria 2017

\section{Erratum to: Theor Appl Climatol}

DOI 10.1007/s00704-017-2140-7

In the abovementioned paper, the authors cite the paper "On the use of robust regression methods in wind speed assessment", written by Soukissian and Karathanasi (2016); however, they have swapped these authors' surnames (i.e., Soukissian and Karathanasi) with their forenames (i.e., Takvor and Flora).

Since bibliometric indices are important in today's academic profiling, we would like to make the following correction to the citation:

Takvor HS, Flora EK (2016) On the use of robust regression methods in wind speed assessment. Renew Energy 99:12871298

with the following:

Soukissian TH, Karathanasi FE (2016) On the use of robust regression methods in wind speed assessment. Renew Energy 99:1287-1298

The original article has been corrected.

The online version of the original article can be found at http://dx.doi.org/ $10.1007 /$ s00704-017-2140-7

Peng Si

spsbox@163.com

1 Tianjin Meteorological Information Center, Tianjin Meteorological Bureau, Tianjin 300074, China

2 Tianjin Marine Meteorological Centre, Tianjin Meteorological Bureau, Tianjin 300074, China 